\title{
Analisis Reduksi Miskonsepsi Mahasiswa Setelah Penerapan Model Pembelajaran ECIRR Pada Materi Stoikiometri
}

\author{
Catur Fathonah Djarwo \\ Program Studi Pendidikan Kimia, Universitas Cenderawasih, Jayapura \\ Email: caturdjarwo@gmail.com
}

\begin{abstract}
Abstrak: Salah satu pokok bahasan yang terdapat dalam materi kuliah kimia dasar 1 adalah stoikiometri. Kesalahan mahasiswa dalam memahami konsep pada pokok bahasan stoikiometri dapat menyebabkan terjadinya kesalahan pemahaman konsep kimia yang lebih lanjut. Kesalahan konsep yang salah, namun dianggap benar oleh mahasiswa disebut dengan miskonsepsi. Model pembelajaran yang tepat untuk mereduksi miskonsepsi adalah model pembelajaran ECIRR. Tujuan dalam penelitian ini adalah untuk mengetahui miskonsepsi sebelum dan setelah pembelajaran dengan menerapkan model pembelajaran ECIRR, kemudian menganalisis reduksi miskonsepsi yang terjadi pada mahasiswa. Populasi dalam penelitian adalah 22 orang mahasiswa semester 1 Pendidikan Kimia yang telah menerima materi Stoikiometri. Penelitian ini menggunakan teknik pengumpulan data yang berupa tes diagnostik dan observasi. Hasil analisis yang diperoleh yaitu persentase rata-rata reduksi miskonsepsi tiap konsepsi pada materi stoikiometri adalah 73,65\%, sedangkan pada tiap mahasiswa adalah $84,72 \%$. Hal ini menunjukkan bahwa model pembelajaran ECIRR dapat mereduksi miskonsepsi mahasiswa pada materi stoikiometri.
\end{abstract}

Kata kunci : Miskonsepsi, ECIRR, Stoikiometri.

\section{PENDAHULUAN}

Lembaga yang berfungsi sebagai tempat untuk belajar dan memberi pelajaran adalah Sekolah (Poerwadarminta, 2006: 1054). Belajar dan memberi pelajaran berkaitan dengan proses pembelajaran. Pembelajaran merupakan pengembangan serangkaian kegiatan untuk menciptakan aktivias belajar baik di dalam dan di luar sekolah (Pribadi, 2009:9). Kegiatan pembelajaran dapat berlangsung pada berbagai tingkat pendidikan yang dimulai dari Taman Kanak-kanak, Sekolah Dasar, Sekolah Menengah Pertama, Sekolah Menengah Atas, hingga Perguruan Tinggi. Pelaksanaan pembelajaran pada berbagai tingkatan tersebut dapat ditunjukkan dengan adanya aktifitas belajar. Kemampuan yang diperlukan dalam aktifitas belajar antara lain kognitif, afektif, dan psikomotor. Kemampuan kognitif mempunyai peran utama dalam proses belajar, yang memungkinkan mahasiswa dapat menguasai materi kuliah lebih efektif dan efisien. Penguasaan materi pelajaran, khususnya pada Fakultas FKIP oleh peserta didik di Perguruan Tinggi dikelompokkan menjadi beberapa jurusan yang salah satunya adalah Jurusan MIPA.
Jurusan MIPA mencakup Matematika, Fisika, Biologi, dan Kimia. Salah satu materi kuliah yang dipelajari mahasiswa pendidikan kimia pada semester ganjil adalah kimia dasar 1. Mempelajari materi kimia membutuhkan pemahaman konsep yang beruntun dan saling berkesinambungan (Yunitasari, dkk, 2013: 182). Pokok bahasan yang terdapat dalam materi kuliah kimia dasar 1 salah satunya adalah stoikiometri. Stoikiometri adalah perhitungan kimia yang menggambarkan semua aspek kuantitatif dari komposisi dan reaksi kimia (Rachmawati dan Johari, 2007: 201). Sub pokok bahasan dalam materi stoikiometri antara lain rumus kimia, tata nama senyawa, persamaan reaksi, hukumhukum dasar kimia, dan perhitungan kimia. Pemahaman konsep-konsep dalam pokok bahasan stoikiometri perlu dipahami dengan baik karena menjadi dasar untuk penguasaan konsep pada mata kuliah selanjutnya. Kesalahan mahasiswa dalam memahami konsep-konsep pada pokok bahasan stoikiometri dapat menyebabkan terjadinya kesalahan pemahaman konsep-konsep kimia yang lebih lanjut. 
Kesalahan konsep yang dianggap benar oleh mahasiswa disebut dengan miskonsepsi. Hasil penelitian Desi (2013: 16-17) terdapat miskonsepsi pada mahasiswa program studi pendidikan kimia

pada pokok bahasan stoikiometri mata kuliah kimia dasar I pada topik materi dan perubahannya $(28,95 \%)$, unsur, senyawa, dan campuran $(13,16 \%)$, persamaan reaksi (48,68\%), hukum- hukum dasar kimia (55,70\%), dan konsep mol (51,64\%).

Miskonsepsi dapat direduksi menggunakan model pembelajaran yang tepat. Salah satu model pembelajaran yang dapat diterapkan adalah model pembelajaran ECIRR. ECIRR merupakan model pembelajaran hasil penyempurnaan dari learning cycles, conceptual change, bridging analogies, microcomputer-based laboratory experiences, dan disequilibration techniques (Wening dalam Istimatus dan Harun (2016:99)). ECIRR adalah singkatan dari Elicit, Confront, Identify, Resolve dan Reinforce. Model pembelajaran ECIRR dapat mengurangi miskonsepsi, terutama pada tahap identify dan reinforce. Pada tahap identify, mahasiswa akan menyadari kesalahpahaman yang mereka alami, dan pada tahap reinforce, siswa akan menekankan konsep baru yang diterima untuk menggantikan yang lama. Penelitian tentang penerapan model pembelajaran ECIRR untuk mereduksi miskonsepsi telah dilakukan oleh para ahli kimia salah satunya pada materi kesetimbangan kimia oleh Istimatus dan Harun (2016).

Penelitian tentang analisis reduksi miskonsepsi mahasiswa setelah penerapan model pembelajaran ECIRR pada materi stoikiometri perlu dilakukan agar pengajar dapat meminimalkan miskonsepsi dengan cara memilih dan menentukan metode pembelajaran yang tepat, agar proses belajar mengajar lebih efektif. Tujuan dalam penelitian ini adalah untuk mengetahui miskonsepsi sebelum dan setelah penerapan model pembelajaran ECIRR pada materi stoikiometri, kemudian menganalisis reduksi miskonsepsi yang terjadi pada mahasiswa.

\section{METODE PENELITIAN}

Penelitian ini menggunakan rancangan deskriptif dan quasi experimental dengan jenis Pre test and Post test. Rancangan deskriptif digunakan untuk mengetahui miskonsepsi mahasiswa selama pembelajaran dengan menggunakan model ECIRR. Rancangan quasi eksperimental digunakan untuk mengetahui hasil belajar siswa yang diajar menggunakan model pembelajaran ECIRR.

\begin{tabular}{ll} 
& \multicolumn{1}{c|}{$\mathbf{O}_{\mathbf{1}} \mathbf{X ~ \mathbf { O } _ { \mathbf { 2 } }}$} \\
Keterangan : \\
$\mathrm{O}_{1} \quad$ : Pre test \\
$\mathrm{X} \quad$ : pembelajaran menggunakan \\
\\
$\mathrm{O}_{2} \quad$ model pembelajaran ECIRR
\end{tabular}

Populasi dalam penelitian adalah 22 orang mahasiswa semester 1 Pendidikan Kimia yang pernah menerima materi Stoikiometri Penelitian ini menggunakan teknik pengumpulan data yang berupa tes dan observasi.

Identifikasi tingkat pemahaman konsep siswa dilakukan dengan menggunakan tes diagnostik, kemudian dihitung dengan menggunakan persentase. Bentuk soal tes berupa 53 soal pilihan ganda. Tahap akhir analisis dilakukan dengan mengolah jawaban mahasiswa berdasarkan tingkat pemahaman mahasiswa sebelum (pre-test) dan setelah (post-test) dilaksanakan pembelajaran ECIRR untuk mengetahui persentase miskonsepsi mahasiswa, menghitung rata-rata reduksi miskonsepsi mahasiswa tiap konsepsi, dan reduksi jumlah miskonsepsi tiap mahasiswa.

\section{HASIL DAN PEMBAHASAN}

Persentase miskonsepsi mahasiswa terhadap materi stoikiometri dianalisis dengan perhitungan persentasi berdasarkan konsep utama antara lain : rumus kimia, tata nama senyawa, persamaan kimia, hukum-hukum dasar kimia, dan perhitungan kimia. Lebih jelasnya dapat dilihat pada tabel 1 berikut: Tabel 1. Persentase Reduksi Miskonsepsi Mahasiswa Tiap Konsepsi Stoikiometri 


\begin{tabular}{|c|c|c|c|c|c|}
\hline No & Konsep yang dianalisis & Soal Ke & $\begin{array}{c}\text { Frekuensi } \\
\text { pre-test }\end{array}$ & $\begin{array}{c}\text { Frekuen } \\
\text { si post- } \\
\text { test }\end{array}$ & $\begin{array}{c}\text { Penuruman } \\
\text { Miskonsepsi } \\
(\%)\end{array}$ \\
\hline & b. Massa rumus relatif & 42 & 5 & 0 & 100 \\
\hline & c. Satu mol zat & 43 & 5 & 2 & 60 \\
\hline & d. Massa molar & 44 & 4 & 1 & 75 \\
\hline & e. Hubunganmol dan massa & 45 & 6 & 1 & 83,33 \\
\hline & f. Volum molar' gas & 46 & 5 & 3 & 40 \\
\hline & g. Rumus volum molar gas & 47 & 4 & 1 & 75 \\
\hline & h. Hukum Gas ideal & 48 & 7 & 0 & 100 \\
\hline & i. Persamaan gas ideal & 49 & 5 & 0 & 100 \\
\hline & j. Kemolaran larutan & 50 & 4 & 2 & 50 \\
\hline & k. Persen massa zat & 51 & 6 & 1 & 83,33 \\
\hline & 1. Pereaksi pembatas & 52 & 6 & 3 & 50 \\
\hline & j. Hidrat & 53 & 7 & 3 & 57,14 \\
\hline \multicolumn{5}{|c|}{ Persentasirata-rata reduksi miskonsepsi } & $73,65 \%$ \\
\hline
\end{tabular}

Setelah diketahui persentase mahasiswa yang mengalami miskonsepsi, maka selanjutnya dilakukan proses reduksi miskonsepsi mahasiswa dengan menerapkan model pembelajaran ECIRR. Setelah proses pembelajaran dengan menerapkan model pembelajaran ECIRR selesai maka dilakukan lagi tes pemahaman konsep akhir.

Tabel 1, menunjukkan bahwa mahasiswa yang mengalami reduksi miskonsepsi paling besar (100\%), terdapat pada 15 konsepsi diantaranya Lambang Unsur, Kation, Anion, Nama Senyawa Ion, Senyawa Basa, Tata Nama Senyawa Basa, Senyawa Garam, Tata Nama Senyawa Garam, Reaktan, Produk, Hukum Lavoisier, Massa Molekul Relatif, Massa Rumus Relatif, Hukum Gas Ideal, dan Persamaan Gas Ideal. Sedangkan persentasi reduksi miskonsepsi setelah dilaksanakan model pembelajaran ECIRR yang paling kecil terjadi pada konsepsi Senyawa Organik sebesar $33,33 \%$. Persentase rata-rata reduksi miskonsepsi tiap konsepsi pada materi stoikiometri yaitu 73,65\%. Analisis reduksi miskonsepsi untuk tiap-tiap soal diuraikan sebagai berikut:

Mahasiswa mengalami reduksi miskonsepsi pada konsepsi atom sebesar $40 \%$. Begitu juga pada konsepsi Tata nama senyawa poliatomik, Reaksi kimia, Koefisien reaksi, Hipotesis Avogadro, dan Volum molar gas.

$50 \%$ reduksi miskonsepsi terjadi pada konsepsi rumus kimia, dimana mahasiswa menganggap bahwa rumus kimia adalah perbandingan atom-atom dalam suatu molekul, bergeser menjadi rumus kimia adalah notasi yang memuat jenis dan perbandingan atom penyusun unsur atau senyawa yang dinyatakan oleh lambang huruf basar dan kecil serta angka. Hal yang sama terjadi pada konsepsi Tata nama senyawa asam, Hukum Proust dan Kemolaran larutan.

Reduksi miskonsepsi terjadi pada pengertian molekul sebesar 57,14\%, miskonsepsi ini terjadi karena mahasiswa beranggapan bahwa senyawa adalah gabungan atom-atom misalnya $\mathrm{H}_{2} \mathrm{O}$, gabungan atom $\mathrm{H}$ dan $\mathrm{O}$ oleh sebab itu disebut gabungan atomatom. $57,14 \%$ reduksi miskonsepsi juga terjadi untuk konsepsi Senyawa poliatomik dan Hidrat.

Stoikiometri yang berasal dari dua suku kata yaitu stoicheion dan metron yang berarti unsur dan mengukur. Mahasiswa mengalami reduksi miskonsepsi sebesar 60\%. Hal ini diikuti juga pada konsepsi Rumus Empiris dan Satu Mol Zat.

Gabungan dari dua atau lebih atom-atom unsur sejenis disebut molekul unsur, mahasiswa mengalami reduksi miskonsepsi sebanyak 66,67\%. Konsepsi senyawa biner mengalami reduksi miskonsepsi yang sama dengan konsepsi molekul unsur, dengan sebaran jawaban sebagai berikut: sebagian mahasiswa yakin dengan pilihan jawaban ' $c$ ' yaitu senyawa yang terdiri lebih dari dua jenis unsur. Kata biner berarti menunjukkan dua, namun mahasiswa tidak yakin bahwa senyawa hanya terdiri dari dua jenis unsur saja, melainkan lebih dari dua jenis unsur. Reduksi yang sama pada konsepsi tata nama senyawa biner dan persamaan kimia, dimana terdapat pada pilihan jawaban mahasiswa yang benar yaitu 'd' persamaan kimia adalah persamaan yang menggambarkan perubahan kimia dari pereaksi menjadi produk.

Tata nama senyawa molekul mengalami reduksi miskonsepsi sebesar $71,43 \%$, diikuti $75 \%$ pada konsepsi senyawa ion, senyawa asam, Massa molar, dan Rumus volum molar gas. Senyawa ion adalah senyawa biner dari logam dan nonlogam, pilihan jawaban yang tepat adalah 'a', namun ada beberapa mahasiswa yang mengalami miskonsepsi untuk senyawa ion dengan memilih jawaban ' $b$ ' yaitu senyawa ion adalah senyawa biner dari logam. Mahasiswa yang mengalami miskonsepsi pada konsepsi senyawa asam 
menurut Arrhenius memilih jawaban yang diyakini benar yaitu ' $b$ ' senyawa ion yang terdiri dari kation basa dan anion sisa asam. Siswa terkeceoh dengan kata asam. Konsepsi yang benar mengenai senyawa asam menurut Arrhenius adalah senyawa yang dalam air dapat melepaskan ion $\mathrm{H}^{+}$(pilihan jawaban 'd').

Rumus molekul mengalami reduksi miskonsepsi setelah pembelajaran ECIRR sebesar $80 \%$ (Tabel 1). Miskonsepsi awal terjadi karena pilihan jawaban tertukar dengan konsepsi rumus empiris. Partikel materi adalah komponen terkecil materi yang masih memiliki sifat yang sama dengan sifat materi tersebut, piihan jawaban yang tepat adalah 'e', sebagian mahasiswa menjawab ' $b$ ' karena siswa terfokus pada kata komponen terkecil selalu adalah atom.

Mahasiswa yang terfokus pada satu jawaban satu saja dapat diasumsikan bahwa mahasiswa tersebut hanya menghafal dan mengingat konsepsi namun tidak memahami konsepsi secara keseluruhan. Mahasiswa hanya melihat terdapat beberapa kata yang dihafal pada konsepsi tersebut, sehingga keliru dalam memilih jawaban, sedangkan mahasiswa yang memiliki sebaran pilihan jawaban dapat diasumsikan bahwa mahasiswa tersebut tidak memahami konsepsi dengan baik.

Model pembelajaran ECIRR sebagai salah satu alternatif model pembelajaran yang dapat mengurangi miskonsepsi. Reduksi miskonsepsi pada materi stoikiometri terjadi pada tahap identify dan reinforce. Pada tahap identify, mahasiswa akan menyadari kesalahpahaman yang mereka alami, dan pada tahap reinforce, siswa akan menekankan konsep baru yang diterima untuk menggantikan yang lama. Sehingga pada posttest yang diberikan mengalami kenaikan ratarata hasil belajar. Dengan demikian terjadi pergeseran pemahaman mahasiswa dari miskonsepsi menjadi paham konsep.

Reduksi miskonsepsi tiap mahasiswa pada materi stoikiometri dapat di lihat pada tabel 2 dan bagan 1 berikut.

Tabel 2. Reduksi Jumlah Miskonsepsi Tiap Mahasiswa

\begin{tabular}{|c|l|}
\hline Jumlah Siswa & $\begin{array}{l}\text { Persentase Reduksi Jumlah } \\
\text { Miskonsepsi Tiap Mahasiswa (\%) }\end{array}$ \\
\hline 2 & Tidak mengalami miskonsepsi \\
\hline 11 & Mengalami reduksi miskonsepsi 100\% \\
\hline 3 & Mengalami reduksi miskonsepsi 75\% \\
\hline 1 & Mengalami reduksi miskonsepsi $66,67 \%$ \\
\hline 2 & Mengalami reduksi miskonsepsi 50\% \\
\hline 1 & Mengalami reduksi miskonsepsi 33,33\% \\
\hline 2 & Tidak mengalami reduksi miskonsepsi \\
\hline Rata-rata & $84,72 \%$ \\
\hline
\end{tabular}

Persentase Reduksi Jumlah Miskonsepsi Tiap Mahasiswa

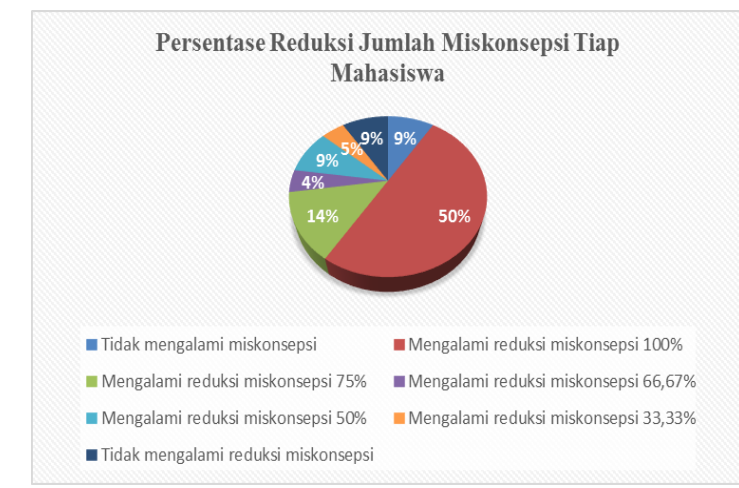

Bagan 1. Diagram Reduksi Jumlah Miskonsepsi Tiap Mahasiswa

Pada tabel 2, dapat diketahui bahwa persentase rata-rata reduksi miskonsepsi tiap mahasiswa adalah $84,72 \%$. Terdapat 2 mahasiswa atau $9 \%$ dari 22 dalam populasi penelitian yang tidak mengalami miskonsepsi. 11 mahasiswa mengalami reduksi miskonsepsi sebesar $100 \%, 3$ mahasiswa mengalami reduksi miskonsepsi sebesar $75 \%, 1$ mahasiswa mengalami reduksi miskonsepsi sebesar $66,67 \%, 2$ mahasiswa mengalami reduksi miskonsepsi sebesar 50\%. Terdapat juga 1 mahasiswa yang hanya mengalami reduksi miskonsepsi sebesar $33,33 \%$ dan 2 mahasiswa yang tidak mengalami reduksi miskonsepsi. Hal ini dapat terjadi karena kurangnya kemampuan mahasiswa dalam memahami konsep pada ketiga level representasi yang meliputi makroskopik, submikroskopik, dan simbolik. 


\section{KESIMPULAN}

Berdasarkan hasil penelitian, dapat disimpulkan bahwa model pembelajaran ECIRR dapat mereduksi miskonsepsi mahasiswa pada materi stoikiometri, baik pada tiap konsepsi maupun pada tiap mahasiswa. Persentase rata-rata reduksi miskonsepsi tiap konsepsi pada materi stoikiometri yaitu $73,65 \%$, sedangkan persentase rata-rata reduksi miskonsepsi tiap mahasiswa adalah $84,72 \%$.

\section{DAFTAR PUSTAKA}

Arikunto, S. (2013). Prosedur Penelitian Suatu Pendekatan Praktik. Jakarta: PT Rineka Cipta.

A. Pribadi, Benny. (2009). Model Desain Sistem Pembelajaran. Jakarta: PT Dian Rakyat.

Desi (2013). Identifikasi Miskonsepsi Mahasiswa Program Studi Pendidikan Kimia pada Pokok Bahasan Stoikiometri Mata Kuliah Kimia Dasar I. http://repository.unsri.ac.id/id/eprint/685 $\underline{9}$ (diakses tanggal 12 Februari 2019)

Hamalik, O. (2009). Proses Belajar Mengajar. Jakarta: Bumi Aksara.

Istimatus Nur Khomaria dan Harun Nasrudin (2016). Penerapan Model Pembelajaran ECIRR Untuk Mereduksi Miskonsepsi Pada Materi Kesetimbangan Kimia Kelas XI MIA di SMA Negeri 1 PACET. Unesa Journal of Chemical Education, 5(1), 98-106

Mahmudah, R. (2013). Identifikasi Miskonsepsi Siswa Pada Konsep Suhu dan Kalor Dengan Menggunakan Peta Konsep dan Wawancara. Skripsi Sarjana Fakultas Sains dan Teknologi UIN Sunan Kalijaga. Yogyakarta: diterbitkan.

Nursiwin, T. (2010). Studi Miskonsepsi Siswa SMA Kelas X Pada Materi Stoikiometri Di SMA Negeri 1 Sentulo Kulonprogo. Skripsi Sarjana Fakultas Sains dan Teknologi Universitas Islam Negeri Sunan Kalijaga. Yogyakarta: tidak diterbitkan.

Nursiwin, T. (2014). Menggali Miskonsepsi Siswa SMA Pada Materi Perhitungan
Kimia Menggunakan Certainty Of Response Index. Artikel Penelitian. Pontianak: diterbitkan.

Poerwadarminta. (2006). Kamus Besar Bahasa Indonesia. Jakarta : Balai Pustaka

Suryawirawati, I G., Ramdhan B., dan Juhanda, AA. (2018). Analisis Penurunan Miskonsepsi Siswa pada Konsep Pemanasan Global dengan Tes Diagnostik (Two-Tier Test) setelah Pembelajaran Predict-Observe-Explain (POE). Journal of Biology Education, Vol 1 No 1 (2018), 93-104

Yunitasari, W., Susilowati, E., dan Nurhayati, N. D. 2013. Pembelajaran Direct Instruction Disertai Hierarki Konsep Untuk Mereduksi Miskonsepsi Siswa Pada Materi Larutan Penyangga Kelas XI IPA Semester Genap SMA Negeri 2 Sragen Tahun Ajaran 2012/2013. JurnalPendidikan Kimia(JPK), Volume 2 (3): 182-190. 